\title{
The Effect of Knowledge Management Processes on Organizational Business Processes' and Employees' Benefits in an Academic Institution's Portal Environment
}

\author{
Fadia M. Hegazy and Kamel E. Ghorab
}

AlHosn University, Abu Dhabi, UAE

Correspondence should be addressed to: Fadia M. Hegazy; f.hegazy@alhosnu.ae

Received date: 17 March 2015; Accepted date: 25 July 2015; Published date: 7 December 2015

Academic Editor: Tereza Otčenášková

Copyright (C) 2015. Fadia M. Hegazy and Kamel E. Ghorab. Distributed under Creative Commons CCBY 4.0

\begin{abstract}
The current study aims at assessing the functional relationships between knowledge management processes and both organizational business processes' and employees' benefits. The assessment is taking place within an academic institution's portal environment. The study particularly investigates the effect of knowledge discovery, knowledge capture, knowledge sharing and knowledge application on business processes' effectiveness, efficiency, and innovation; and employees' learning, adaptability, and job satisfaction. Statistical analysis is performed using the PLS method on a structural equations framework.Consistent with previous research, knowledge sharing produces the highest effect on organizational business processes' and employees' benefits.
\end{abstract}

Keywords: Knowledge Management Effects, Corporate Portal, Organizational Business Processes' Benefits, Employees' Benefits

\section{Introduction}

Data and information are different from knowledge although still interrelated. On one hand, data represent raw numbers or words about facts, observations, or perceptions. On one hand, information is processing data of relevance and purpose. On the other hand, knowledge is roughly, useful or

actionable
information.Knowledge is information that's relevant to a decision. It is good explanations, and it is solutions (even if partial) to problems people had.

Knowledge has become one of the most highly valued commodities in the modern economy. Further, knowledge is considered the principal tool of competitiveness and innovation in the

Cite this Article as: Fadia M. Hegazy and Kamel E. Ghorab(2015), "The Effect of Knowledge Management Processes on Organizational Business Processes' and Employees' Benefits in an Academic Institution's Portal Environment,"Communications of the IBIMA, Vol. 2015 (2015), Article ID 928262, 
composition of commodity chain to the broader processes of regional and national economic development (for example, Barney (1995), Bhatt (2000), Daniels and Bryson (2002), and Shapira et al. (2006)). The new paradigm is that within the organization knowledge must be shared in order for it to grow. Uriate (2008) mentioned that sharing knowledge among its management and staff grows stronger and becomes more competitive.

Knowledge Management (KM) is an approach to achieve organizational objectives by making the best use of knowledge, or as noted by BecerraFernandez et al. (2004) "doing what is needed to get the most out of knowledge resources."Skyrme (2001) defines knowledge management as "the explicit and systematic management of vital knowledge-and its associated processes of creation, organization, diffusion, use and exploitation". In the modern economy, according to Malone (2002), KM plays a key role and is widely used by many firms as one of the most effective means of achieving success in the information age.

The information technologies that support KM throughout an organization are referred to as Knowledge Management Systems or KMS (see: Holsapple (2003), Park and Kim (2006), Sedighi (2006), and Zhang and Zhao (2006), to name a few).In the book byTurban et al. (2011), KMS are defined as computer-based information systems (including databases, data warehouses, document management systems, and artificial intelligence) that manage knowledge throughout the organization; their goal is to identify, capture, store, maintain, and deliver (retrieve, transfer, and disseminate) useful knowledge in a meaningful form to everyone who needs it, anyplace and anytime, within the organization. Structured or unstructured, explicit or tacit knowledge from internal or external sources can be stored in an organizational KMS (Davenport and Prusak (1998)).
The use of KMS to support KM processes enables KM to achieve its goals. KMS improve effectiveness and efficiency of organizational KM.Several empirical studies in different countries provided evidence on the significance of KM and KMS such as Gold et al. (2001), and Jennex (2008) in the US, Chong (2006) in Malaysia, Liu and Tsai (2007) and Wu and Wang (2006) in Taiwan, and Al-Busaidi and Olfman (2005) in Oman.

KMS is considered as a type of Decision Support Systems (DSS).Well-designed decision supports systems guide decisionmakers in their efforts towards achieving their objectives through providing them with detailed information tailored specifically to their needs. A sizable literature looks into the effect of using DSS on decision making efficiency and effectiveness. One can review many of these studies in Dickson, Senn and Charvancy (1977), Jenkins (1977), Ives, Hamilton and Davis (1980), Courtney, DeSanctis and Kasper (1983), Jarvenpaa (1985), Sharda et al. (1988), Ganguly and Gupta (2005).

In relation to the current study, we believe that there is a great deal of understanding in the published literature (as will be seen shortly) that KM and KMS positively influence the performance of business processes. At the same time, the same literature still points out to a need for empirical research that shows that influence (Robles-Flores (2011)).Many other studies have reported that the use of KM and KMS result in business processes' benefits such as effectiveness, efficiency, innovativeness, productivity, and performance; and employees' benefits such as effective decision-making, better learning, adaptability, satisfaction, and performance, and many others (see Mohamed and Jalal (2011), Dermol (2011), Alavi and Linder (2001), BecerraFernandiz, Gonzalez and Sabherwal (2004), and Davenport and Prusak (1998)). 
A review of the corporate portals literature reveals that there are limited studies that have focused on issues related to their Web design quality (Yang, Cai, Zhoue and Zhou (2005)). There are some studies in the KM literature, such as Chung and Lee (2007), Liu and Tsai (2007), Jiang and Liab (2008), Tiwana (2004), and Norman (2002) that have investigated the impact of $\mathrm{KM}$, but at very limited KM processes and or benefits scales. Assessing the specific impact of each $\mathrm{KM}$ process independently has not been addressed adequately. Investigating the activities required for the systematic handling of knowledge resources is necessary (Heisig (2009)).

Relating KM and business processes is a critical success factor for KM and for effective use of corporate portal (Benbya et al. (2004)). Likewise, employees perceived that KMS benefits are a significant determinant of their use $\mathrm{CWu}$ and Wang (2006), and Becerra-Fernandez et al. (2004)).Therefore, it is important for organizations to recognize the effect of supporting corporate portals KM processes on business processes and employees.

The use of corporate portals in universities is growing worldwide ( $\mathrm{Li}$ and Wood (2005)). There is some literature on the use of corporate portals in academic institutions (Al-Busaidi (2009), Pino and Doucet (2007), Li and Wood (2005)); however, empirical studies that assess the impact of supporting KM processes through corporate portals on business processes and employees in the academic context are very limited. Al-Busaidi (2010)investigated this impact in an academic institution. Her study investigated KM processes based on Gold et al.'s (2001) classification. Studies are called for to investigate this impact based on different KM processes classifications.

United Arab Emirates' (UAE) private universities have been under growing pressure from their governmental counterparts to become more effective, efficient, innovative, and competitive. Their target has been to capture a reasonable market share of the higher education industry growing total demand. While anxiously searching for solutions, these universities have learnt that one of the most important competitive weapons is an efficient and effective knowledge management system. A system that is capable of increasing their business revenues while decreasing average operations costs.

Based on the above, the following is the research main question, which will drive the current study: "To what extent do Knowledge Management Systems influence the performance of business processes' and employees benefits?"

The current study is an attempt to investigate the influence of corporate portal services on business processes' and employees' benefits. In order to answer the above main research question, the study seeks to find answers to such basic questions as:

a. What kind of benefits can this portal realize?

b. What Knowledge Management Processes have greater impact on Business Processes' Performance?

c. What Knowledge Management Processes have greater impact on employees' benefits?

d. What are the functional relationships between corporate portal services and its end users and business processes?

\section{Literature Review}

\section{Why Use Knowledge Management?}

The environment in which organizations operate and make decisions today is becoming more and more difficult to deal with and predict. Business environment factors can be divided into four major 
categories: markets, consumer demands, technology, and societal (Turban et al. (2011)). The intensity of most of these factors increases with time, leading to more pressures, more competition, and so on. In addition, organizations and departments within organizations face decreased budgets and amplified pressures from top managers to improve performance in terms of profitability, growth, and risk.

Based on related literature, BacerraFernandez et al. (2004) note four trends that drive knowledge management: increasing domain complexity, accelerating market volatility, intensified speed of responsiveness, and diminishing individual experience. First, intricacy of internal and external processes, increased competition, and the rapid advancement of technology all contribute to increasing domain complexity. Second, the pace of change, or volatility, within each market domain has increased rapidly in the past decade. Third, the time required to take action based upon subtle changes within and across domains is decreasing. Fourth, high employee turnover rates have resulted in individuals with decision-making authority having less tenure within their organizations than ever before.

Adopting knowledge management, organizations can improve their capabilities of creating, managing, sharing and applying their knowledge, sharpen their business intelligence, enhance their managerial decisions efficiency and effectiveness, and ultimately achieve better business performance (Herschel and Jones (2005), and Lo and Chin (2009)).

Knowledge management is rooted in the concepts of organizational learning and organizational memory. When members of an organization collaborate and communicate ideas, teach, and learn knowledge is transformed and transferred from individual to individual (Bennet et al. (2003)).

\section{Knowledge Management Processes}

In his paper, Bray (2013) identified and reviewed four perspectives within the literature surrounding knowledge management (KM) research at the organizational level: information systems, management, organizational learning, and strategy perspectives. The current study is concerned with the information systems perspective.

Alavi and Leidner's (2001) MIS Quarterly article represents the seminal review piece on KM and information systems; often cited in subsequent works. Their article frames the knowledge-based view of the firm extending earlier research by Nonaka (1994), and Grant (1996), and Argote and Ingram (2000) in this area.

Specifically, Alavi and Leidner (2001) propose that knowledge represents information possessed in the minds of individuals, specifically "personalized information (which may or may not be new, unique, useful, or accurate) related to facts, procedures, concepts, interpretations, ideas, observations, and judgments."Their review article suggests other alternative representations of knowledge as well, to include knowledge as representing a state of mind, object, process, access to information, or a capability. In each case, information systems play roles in supporting the "management" of knowledge.

Additionally, Alavi and Leidner (2001) develop a framework for analysis of the supporting role of an information system with KM; specifically four sets of socially enacted, interdependent knowledge processes:
a. Knowledge creation
b. Knowledge sharing (to include storage and retrieval)
c. Knowledge transfer 


\section{d. Knowledge application}

Gold et al. (2001) also provided a similar classification, but with a new KM dimension. They indicated that the capability of the organizational $\mathrm{KM}$ is assessed by incorporating tools and mechanisms that support not only knowledge acquisition, knowledge conversion, knowledge application, but also knowledge protection. However, BecerraFernandez et al. (2004) classified these processes as knowledge discovery, knowledge capture, knowledge sharing, and knowledge application. In conclusion, Heisig (2009) had summarized and analyzed about 160 frameworks of KM processes. His analysis indicated that the most frequent categorizations of $\mathrm{KM}$ processes are: identify, create, store, share, and apply knowledge.

The current study adopts BecerraFernandez et al.'s (2004) framework of the KM processes. This framework has been intensively tested and hence accepted in the KM research. According to BecerraFernandez et al. (2004), 'Knowledge discoveryis defined as the development of new tacit or explicit knowledge from data and information or from the synthesis of prior knowledge. Knowledge capture is defined as the process of retrieving either explicit or tacit knowledge that resides within people, artifacts, or organizational entities.Knowledge sharingis the process through which explicit or tacit knowledge is communicated to other individuals. Finally, knowledge application process supports the process through which some individualsutilize knowledge possessed by other individuals without actually acquiring, or learning that knowledge."

\section{Corporate Portal and Knowledge Management}

Akporiaye (2007) defines a corporate portal as "a Web-based concept that serves as a single gateway to a company's information and knowledge base for employees and other stakeholders."
The real value of a portal-based approach as it applies to business performance management is that the information delivered to the user is targeted and profile-driven. Thus, the right people get the right information at the right time.

One of the advantages of portals is that their use could bring down the cost of training. Portals advocate user-defined workspaces and encourage collaboration."

According to Benbaya et al. (2004), there are several features and tools that corporate portals can provide. They include core capabilities, supporting capabilities and Web services. First, core capabilities of the portal include collaboration, integration, publication, search, personalization, and taxonomy. Second, supporting capabilities include security, scalability, and profiling. Third, Web services include creating, managing, accessing, and maintain Web sites. Based on these features, a portal can play a major role on organizational knowledge management. It provides tools for knowledge creation (discovery), knowledge retrieval and storage (capture), knowledge exchange (sharing) and knowledge use (application).

The literature review suggests corporate portals include several features and tools that support organizational processes. These processes may result in organizational and individual benefits.

Alavi and Lidner (1999) found that the perceived benefits of KMS can be categorized as process outcomes (enhanced communication, increases staff participation, and improved efficiency) and organizational outcomes (financial: increased sales, decreased cost and improved service and marketing; and general: consistent proposals to multinational clients, improved project management and personnel reduction).

Based on a qualitative study, Nevo and Chan (2007) indicated that KMS has many 
expected benefits.These benefits include improved productivity, effectiveness, efficiency, responsiveness, communication innovation and market share.

Becerra-Fernandez et al. (2004) provided a comprehensive categorization of KM benefits:

1. Employees' benefits (i.e., learning, adaptability, and job satisfaction);

2. Business processes benefits (i.e., effectiveness, efficiency, and innovation);

3. Products benefits (i.e., value-added products, knowledge-based products); and

4. Organizational benefits (i.e., return on investment as a direct impact, and economies of scale and scope and sustainable competitive advantage as indirect impacts).

On the Organization level, BecerraFernandez et al. (2004) define:

1. Effectiveness as performing the most suitableprocesses and making the best possibledecisions,

2. Efficiency as performing the processes quicklyand in a low-cost fashion, and

3. Degree of Innovation as performing the processes in acreative and novel fashion that improveseffectiveness and efficiency - or at leastmarketability.

At the Employee level, Becerra-Fernandez et al (2004) define:

1. Learning as acquiring tacit knowledge (expertise) from available written or printed materials (explicit knowledge),
2. Adaptability as employees' ability to anticipate changes and be able to react to them, and

3. Job Satisfaction that will be facilitated as the result of employees' increased knowledge, improved market value, and greater on-the-job performance.

The current study adopts BecerraFernandez at al.'s (2004) classification to examine $\mathrm{KM}$ influence on business processes' and employees' benefits. Products and organizational benefits are not included in this study because they are better assessed at the managers' level not the users' level.

\section{Knowledge Management, Business Processes' and Employees' Benefits}

\section{Impact on Organization Effectiveness}

According to Becerra-Fernandez et al. (2004), effectiveness enables the organization to:

a. Perform the most suitableprocesses and make the best possibledecisions,

b. Become more effectiveby helping them to select and perform the mostappropriate processes, and

c. Quickly adapt their processes according to the current circumstances, thereby maintaining process effectiveness in changing times.

2. Impact on Organization Efficiency

As explained by Becerra-Fernandez et al (2004), efficiency enables the organization to:

a. Perform the processes quicklyand in a low-cost fashion,

b. Be more productive and efficient, 
c. Improve the interrelated aspects of organizational processes (effectiveness, efficiency, innovativeness) through several means, including better knowledge being imparted to individuals (through exchange, socialization, and so on), and

d. Improve these processes through other means, including better knowledge being imparted to individuals (through exchange, socialization, and so on) and the provision of workable solutions (through directions and routines), for employees to solve the problems faced in their tasks.

3. Impact on Organization Degree of Innovation of the Processes

According to Storck and Hill (2000), innovation enables the organization to:

a. Perform the processes in acreative and novel fashion that improveseffectiveness and efficiency - or at leastmarketability,

b. Produce innovative solutionsto problems as well as to develop more innovativeorganizational processes through increasingly rely on knowledgeshared across individuals, and

c. Enhance process innovation through enabling riskier brainstorming.

4. Impact on Employee Adaptability

Based on Becerra-Fernandez et al. (2004), employees are likely to adapt when they interactwith each other; thus they are:

a. More likely to expect change,

b. Able to continually learn from each other, thus they are likely to possess the information and knowledge needed to adapt whenever organizational circumstances so require,

c. Less likely to be caught by surprise, and

d. Aware of new ideas and be involved in free-flowing discussions not only prepare them to respond to changes, but they also make them more likely to accept change.

5. Impact on Employee Learning

KM can affect the organization's employees in several ways:

a. It can facilitate their learning (from each other as well as from external sources). This learning by individual employees allows the organization to become constantly growing and changing in response to the market and the technology (Sabherwal (2008)),

b. It can help enhance the employee's learning and exposure to the latest knowledge in their fields. This can be accomplished in a variety of ways including externalization and internalization, socialization, and communities of practice.

\section{Impact on Employee Satisfaction}

Bontis (2003) found that in organizations havingmore employees sharing knowledge with oneanother, turnover rates were reduced, therebypositively affecting revenue and profit:

a. Employees feel better because of theirknowledge acquisition and skill enhancement,

b. Employees' market value is enhanced relative toother organizations' employees, 
c. KM also provides employees with solutions toproblems they face in case those same problems have been encountered earlier, andeffectively addressed,

d. Providing tried-and-tested solutions (eg, via thedirection mechanism) amplifies employees ' effectiveness in performing their jobs,

e. Amplifying employees' effectiveness in performing their jobs through providing tried-andtested solutions. This helps keep those employees motivated, for a successful employee would be highly motivated while an employee facing problems in performing his job would likely be demotivated (Becerra-Fernandez et al. (2004)), and

- Additional increases in employee job satisfaction are derived from KM practices: mentored and trained are excellent motivators, and communities of practice provide intimate and socially validated control over their own work practices (Brownan andDuguid (1991)).

f. Thus, as a result of their increased knowledge, improved market value, and greater on-the-job performance, KM facilitates employees' job satisfaction.

\section{Prior Empirical Studies on Knowledge Management Processes and Benefits}

The literature has very limited empirical studies that provided in depth investigations of the benefits of supporting KM processes through a corporate portal. However, there are several empirical quantitative studies that generally examined the impact of KM and KMS. For example, Gold et al (2001) found that knowledge infrastructure capability (technology, structure, and culture) and knowledge process capability (acquisition, conversion, application, and protection) improve organizational effectiveness in terms of innovation, adaptability, efficiency and market responsiveness.Lee and Choi (2003) found also that KM improves organizational effectiveness measured by organizational members' perceptions of the degree of the overall success, market share, profitability, growth rate, and innovativeness of the organization in comparison with key competitors.

Nevertheless, very little empirical studies examined the specific impact of each of the KM processes independently. Few studies conducted investigation at very limited KM processes and/or benefits scales. There are a number of empirical studies that investigated the effect of knowledge acquisition. For example, Chang and Lee (2007) empirically verified the effects of knowledge acquisition, knowledge storage, and knowledge diffusion on organizational innovation.Liu and Tsai (2007) found that KM (knowledge acquisition, knowledge creation, knowledge storage and knowledge sharing) through KMS positively improve organizations' operating performance. Jiang and Lia (2008) confirmed the effects of knowledge sharing and knowledge creation on forms' innovative performance.

On the impact of knowledge application, Liu (2003) empirically found that knowledge application as a dimension of KMS use improves individual learning. Al-Busaidi (2005) empirically found that knowledge utilization results in individual benefits, which were assessed by measurements related to effectiveness, efficiency, innovation and learning. Jennex and Olfman (2006) identified that the utilization of KMS results in improved individual productivity in terms of decision making, root cause analysis, problem resolution, timeliness, and operability assessment documentation; this improved individual productivity further positively impacts organizational 
productivity. In the context of knowledge portal, Toe and Men (2008) found that the utilization of knowledge portal improves firms' performance. Also, De Carvalho, Ferreira, Choo and De Silva (2007) found the usage of enterprise portal improves sense making, knowledge creation and decision making.

The above cited empirical studies showed that knowledge acquisition (or creation) and knowledge sharing are the most investigated KM processes. Moreover, the benefits, highlighted in these cited studies fall within Becerra-Fernandez et al.'s benefits classification.

\section{Research Design}

\section{Hypotheses Development}

Becerra-Fernandez et al. (2004) identify that knowledge management relied on four main kinds of knowledge management processes as follows: discovery, capture, sharing, and application (the left side in Figure 1).

1. Knowledge Discovery.Knowledge discoverymay be defined as the development of new tacit (includes insights, intuitions, and hunches) or explicit knowledge (refers to knowledge that has been expressed into words and numbers) from data and information or from the synthesis of prior knowledge. The discovery of new explicit knowledge relies most directly on combination, whereas the discovery of new tacit knowledge relies most directly on socialization. Knowledge discovery is essential for the establishment of organizational memory (BecerraFernandez et al. (2004), and Davenport and Prusak (1998)). Corporate portals provide a rich working space that permits searching, accessing, processing, and querying content from different sources.They also provide collaboration and communication tools.Corporate portals speed up business processes through rapid access to relevant and accurate corporate information and knowledge (Gurgué (2002), and Turban et al. (2009)). They eliminate delays, frustration and inefficiency. Thus, corporate portals enable efficient and effective knowledge discovery. Empirical studies by Chang and Lee (2007), and Jiank and Lia (2008) found that knowledge acquisition (discovery) significantly improves performance and innovation. Knowledge acquisition through corporate portals also promotes learning. Corporate Portals integrate collaboration and communication tools (email system, chats, discussion forums, etc.). Collaborations and interactions between individuals promote learning (Teece (1998)). Employees' adaptability is highly related to their learning capability. As knowledge discovery enables employees to learn from each other, and from organizational knowledge bases, employees will most likely have enough knowledge that enables them to anticipate changes, deal with these changes, get used to new requirements, and manage their work as it is needed (BecerraFernandez et al. (2004)). Likewise, innovation is closely related to learning.The higher the learning is, the greater the innovation (Weerawardena, O'Cass and Julian (2006)). Given all these perceived business processes' and employees' benefits, knowledge discovery may contribute to employees' job satisfaction. Users' satisfaction may result from net benefits resulted from the system use (DeLone and McLean (2003), BecerraFernandez et al. (2004), Jennex and Olfman (2006), and Jennex (2008)).

Knowledge Discovery Systems support two KM sub-processes associated with knowledge discovery:

First, combination. As put by Nonaka (1994), combination can be used to discover new explicit knowledge based on synthesizing existing multiple bodies of explicit knowledge (and/or data and/or information) to create more complex sets of explicit knowledge. For example, when creating a new study plan for a program, explicit data, information, and knowledge embedded in prior study plans for the same 
program (or different programs) may be combined into the new study plan. Technologies facilitating combination include knowledge discovery systems, databases, and Web-based access to data.

Second, socialization.Becerra-Fernandez and Sabherwal (2010) predicate that socialization and informal conversations can be used to facilitate the synthesis of tacit knowledge across individuals, and therefore enable the discovery of new tacit knowledge through joint activities rather than written or verbal instructions.Davenport and Prusak (1998) described how conversations at the water cooler helped knowledge sharing among groups at IBM. Mechanisms that facilitate socialization include apprenticeships, employee rotation across areas, conferences, brainstorming retreats, cooperative projects across departments, and initiation process for new employees.

Related literature (e.g., Song (2008)) suggests strong and positive relationship between knowledge discovery and performance measures. Further, when discovered knowledge is used appropriately, a significant and positive relationship is observed between knowledge discovery and organizational performance (Lyles and Salk (1996), Seleim and Khalil (2007)).

Thus, the following hypotheses are examined:

\begin{abstract}
Hypothesis 1a: Supporting knowledge discovery through a corporate portal is positively associated with business processes' effectiveness.
\end{abstract}

Hypothesis 1b: Supporting knowledge discovery through a corporate portal is positively associated with business processes' efficiency.

Hypothesis 1c: Supporting knowledge discovery through a corporate portal is positively associated with business processes' innovation.

Hypothesis 1d: Supporting knowledge discovery through a corporate portal is positively associated with employees' learning.

$\begin{array}{lcc}\begin{array}{l}\text { Hypothesis } \\ \text { knowledge } \\ \text { corporate } \\ \text { associated } \\ \text { adaptability. }\end{array} & \begin{array}{c}\text { 1e: } \\ \text { portal iscovery } \\ \text { with }\end{array} & \begin{array}{c}\text { Supporting } \\ \text { through a } \\ \text { positively } \\ \text { employees' }\end{array} \\ \begin{array}{l}\text { Hypothesis } \\ \text { knowledge }\end{array} & \begin{array}{l}\text { discovery through a } \\ \text { porporate }\end{array} \\ \begin{array}{l}\text { portal is positively } \\ \text { associated with employees' job }\end{array} \\ \text { satisfaction. }\end{array}$




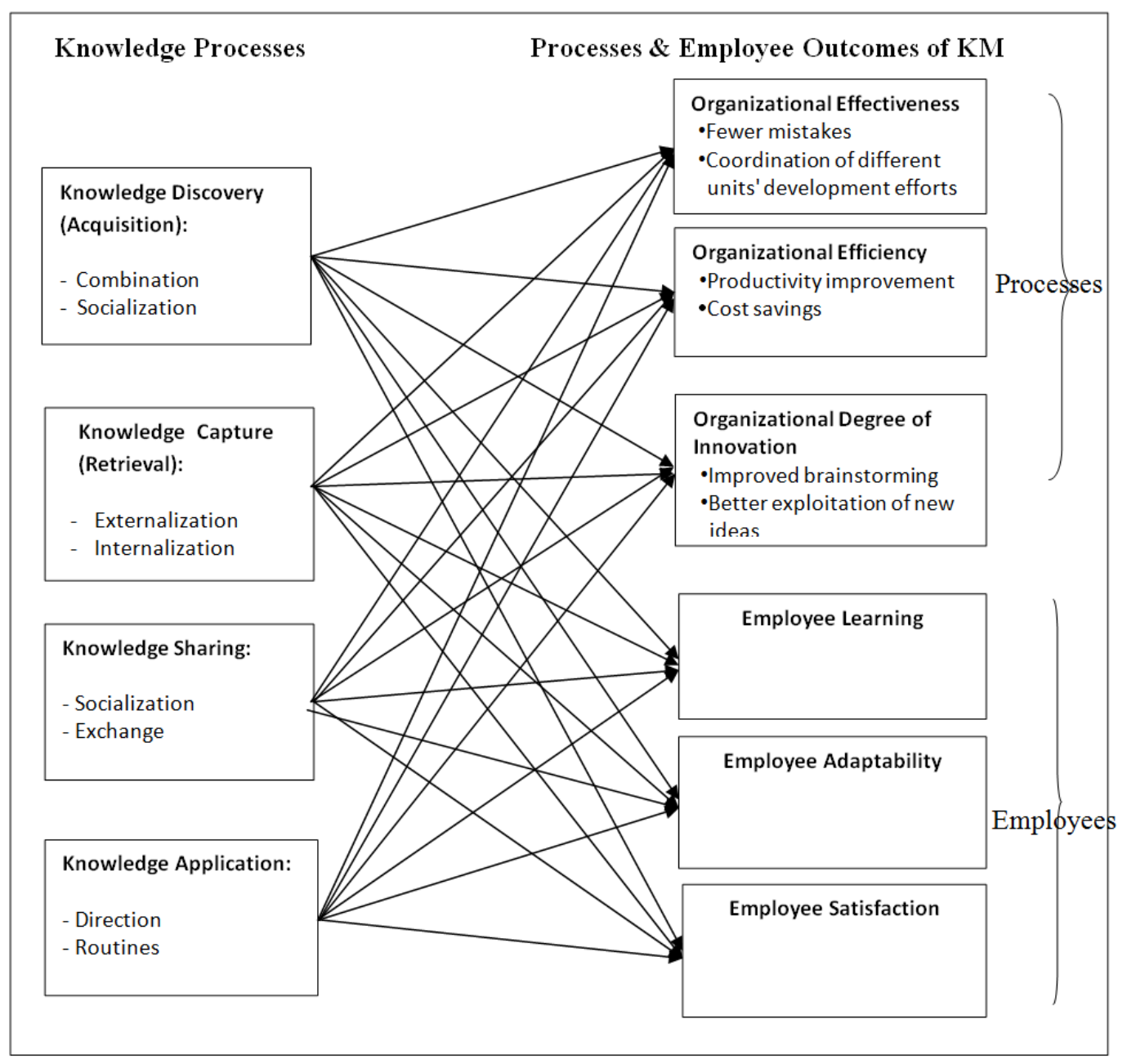

Figure 1: The Study Model

2. Knowledge Capture. Knowledge capture may be defined as the process of retrieving either explicit knowledge (that may reside in a manual or similar document or file but few people might be aware of) or tacit knowledge (that may reside within people, artifacts, or organizational entities) (Becerra-Fernandez et al. (2004)). It is important to obtain the tacit knowledge from individuals' minds as well as the explicit knowledge from the manuals or similar documents, and make this knowledge available to others and to facilitate its sharing within the whole organization.
As discussed above, corporate portals provide rich common content that enables retrieving relevant content from explicit and tacit sources of knowledge through the sub-processes of externalization and internalization of knowledge.Employing different knowledge capture system tools, corporate portals speed up business processes, enable making better business choices, and help to adapt to changed circumstances through access to relevant, well-documented and integrative corporate information and knowledge (Alavi, et al. (2006)). Thus, corporate portals enable efficient and effective knowledge capture. 
Knowledge capture systems support the process of retrieving either explicit or tacit knowledge that resides within people, artifacts, or organizational entities (organizational units, organizations, interorganizational networks).These systems can help capture knowledge that resides within or outside organizational boundaries including within consultants, competitors, customers, suppliers, and prior employers of the organization's new employees. Knowledge capture systems rely on mechanisms and technologies that support externalization and internalization. The development of models or prototypes, and the articulation of stories are some examples of mechanisms that enable externalization. Learning by observation and face-to-face meetings are some of the mechanisms that facilitate internalization (Becerra-Fernandez et al. (2004)).

According to Nonaka and Takeuchi (1995),externalizationinvolves converting tacit knowledge into explicit forms such as words, concepts, visuals, or figurative language (e.g., metaphors, analogies, and narratives).An example of externalization is a consultant team writing a document that describes the lessons the team has learned about the client organization, client executives, and approaches that work in such an assignment. This captures the tacit knowledge acquired by the team members.

On the other hand,internalizationinvolves converting explicit knowledge into tacit knowledge. It represents the traditional notion of learning. An example of internalization is a new software consultant reading a book on innovative software development and learning from it.This learning helps the consultant, and his/her organization, capture the knowledge contained in the book.

Technologies can also support knowledge capture by facilitating externalization and internalization.Externalization through knowledge engineering is necessary for the implementation of intelligent technologies such as expert systems and case-based reasoning systems. A knowledge developer converts human know-how into machineready "say-how" by using an iterative process of articulation, a series of refinement cycles, or rapid prototyping, in which the computer's performance is compared to that of the human expert.

Technologies that facilitate internalization include computer-based communication, electronic brainstorming, protocol analysis, and computer-based simulations. For example, an individual can use communication facilities to internalize knowledge from a message sent by another expert or an Artificial Intelligence-based knowledge-acquisition

system.Furthermore, computer-based simulations can also support individual learning. Both knowledge capture mechanisms and technologies can facilitate externalization and internalization within or across organizations.

According to Danning (2000), KMS that supports externalization:

a. Can help managers and employees actively think about the implications of change, and the threats and opportunities for their organization's future,

b. Can exploit the interactive nature of communication,

c. Provides a vehicle for conveying tacit knowledge,

d. Can communicate a complex multidimensional idea by actively involving the listeners in the creation of the idea in the context of their own organization,

e. Fosters innovation: Innovation is triggered by the inter-relatedness of ideas.

f. Helps launching and nurturing communities: In many large organizations, the formation of 
communities of practice enables the grouping of professionals who come together voluntarily together to share similar interests and learn from each other,

g. Enhances technology: Communities of practice and storytelling can enable us to interact with our neighbors and remain connected when we want to, providing us with "tranquility yet connectedness.", and

h. Promotes individual growth: The world of storytelling is one that proposes avoiding adversarial contests and win-win for all sides: the knowledge seeker and the knowledge-provider.

Therefore, the following hypotheses are examined:

\begin{abstract}
Hypothesis 2a: Supporting knowledge capture through a corporate portal is positively associated with business processes' effectiveness.
\end{abstract}
Hypothesis 2b: Supporting knowledge capture through a corporate portal is positively associated with business processes' efficiency.

\begin{tabular}{|c|c|c|}
\hline $\begin{array}{l}\text { Hypothesis } \\
\text { knowledge } \\
\text { corporate } \\
\text { associated w }\end{array}$ & $\begin{array}{l}\text { 2c: } \\
\text { capture } \\
\text { portal is } \\
\text { with business }\end{array}$ & $\begin{array}{l}\text { Supporting } \\
\text { through a } \\
\text { positively } \\
\text { ss processes' }\end{array}$ \\
\hline $\begin{array}{l}\text { Hypothesis } \\
\text { knowledge } \\
\text { corporate } \\
\text { associated w }\end{array}$ & $\begin{array}{l}\text { 2d: } \\
\text { capture } \\
\text { portal is } \\
\text { ith employee }\end{array}$ & $\begin{array}{l}\text { Supportin } \\
\text { through } \\
\text { positivel } \\
\text { ees' learning }\end{array}$ \\
\hline $\begin{array}{l}\text { Hypothesis } \\
\text { knowledge } \\
\text { corporate } \\
\text { associated }\end{array}$ & $\begin{array}{l}\text { 2e: } \\
\text { capture } \\
\text { portal is } \\
\text { with }\end{array}$ & $\begin{array}{l}\text { Supportin } \\
\text { through } \\
\text { positive } \\
\text { employee }\end{array}$ \\
\hline
\end{tabular}

\begin{abstract}
Hypothesis 2f: Supporting knowledge capture through a corporate portal is positively associated with employees' job satisfaction.
\end{abstract}

3. Knowledge Sharing. Knowledge sharing is the process through which knowledge (whether explicit or tacit) is communicated to other individuals. Three important clarifications are in order. First, according to Jensen and Meckling (1996), knowledge sharing means effective transfer, so that the recipient of knowledge can understand it well enough to act on it. Second, what is shared is knowledge rather than recommendations based on the knowledge (Becerra-Fernandez et al. (2004)). Third, knowledge sharing may take place across individuals as well as across groups, departments, or organizations (Alavi and Leidner (2001)).

Sharing knowledge is clearly an important process in enhancing organizational innovativeness and performance. If knowledge exists at a location that is different from where it is needed, either knowledge sharing or knowledge utilization without sharing is necessary (Stewart (2000)).

Depending on whether explicit or tacit knowledge is being shared, exchange or socialization processes are used. Socialization, focuses on the facilitating the sharing of tacit knowledge across individuals.This can happen through employee rotation across departments, conferences, brainstorming retreats, cooperative projects, or initiation. According to Becerra-Fernandez et al. (2004), there is no intrinsic difference between the socialization process when used for knowledge discovery or knowledge sharing, although the way in which the process may be used could be different. For example, when used to share knowledge, a face-to-face meeting could involve a question-and-answer session between the sender and recipient of 
knowledge, whereas when used to create knowledge a face-to-face meeting could take more the form of a debate or joint problem-solving.

Exchange, in contrast to socialization, focuses on the sharing of explicit knowledge. It is used to communicate or transfer explicit knowledge among individuals, groups, and organizations (Grant (1996)). In its basic nature, the process of exchange of explicit knowledge does not differ from the process through which information is communicated. An example of exchange is a product design manual being transferred by one employee to another, who can then use the explicit knowledge contained in the manual. Exchanging a document could also be used to transfer information.

Mechanisms and technologies that were discussed above supporting socialization in knowledge discovery systems also play an important role in knowledge sharing systems. In addition, knowledge sharing systems also utilize mechanisms and technologies that facilitate exchange. Some of the mechanisms that facilitate exchange are memos, manuals, progress reports, letters, and presentations.Technologies facilitating exchange include groupware and other team-collaboration mechanisms; Web-based access to data and databases; and repositories of information, including best practice databases, lessons learned systems, and expertise locator systems (Becerra-Fernandez et al. (2004)).

Not only knowledge sharing represents an important prerequisite for a successful knowledge application, but also it is an essential ingredient for an efficient and effective organizational knowledge management. Beccera-Fernandez et al. (2004) argue that knowledge management can improve the interrelated aspects of organizational processes (effectiveness, efficiency, and innovativeness) through several means, including better knowledge being imparted to individuals (through exchange, socialization, and so on).
Two main capabilities of corporate reports are content integration and personalization. Banbya et al. (2004) postulate that corporate portals synchronize knowledge from different sources. Hence, they provide a single personalized integrated view of the organizational intellectual capital.Combining and integrating knowledge reduces redundancy and improves efficiency (Davenport and Prusak (1998)). Structuring and organizing knowledge makes it easier to access and disseminate it. Furthermore, the process of combining, integrating and converting knowledge through corporate portals impacts business processes' innovation. Nonaka and Takeuchi (1995) argue that firm's innovativeness results from growing its knowledge base or integrating its existing knowledge into new syntheses. Newell et al. (2003) found that the implementation of ERP, which standardizes and integrates organizational knowledge and information, and KM systems simultaneously, promotes both innovation as well as efficiency. Weerawardena et al. (2006) found that innovation is also closely related to learning. Consequently, as indicated above, improved employees' learning enhances employees' adaptability; and all these perceived benefits may result in enhancing employees' job satisfaction.

Therefore, the following hypotheses are examined:

Hypothesis $\begin{gathered}\text { 3a: } \\ \text { knowledge sharing through a } \\ \text { thring } \\ \text { corporate portal is positively }\end{gathered}$
associated with business processes'
effectiveness.

$\begin{aligned} & \text { Hypothesis } \\ & \text { knowledge } \\ & \text { sharing } \\ & \text { corporate } \begin{array}{c}\text { Supporting } \\ \text { portal is positively } \\ \text { associated with business processes' } \\ \text { efficiency. }\end{array} \\ & \begin{array}{l}\text { Hypothesis } \\ \text { knowledge }\end{array} \text { sharing through a } \\ & \text { corporate portal is positively }\end{aligned}$


associated with business processes' innovation.

Hypothesis $3 \mathrm{~d}$ : Supporting
knowledge sharing through a
corporate portal is positively
associated with employees' learning.

$\begin{array}{lcr}\text { Hypothesis } & \text { 3e: } & \begin{array}{c}\text { Supporting } \\ \text { knowledge } \\ \text { sharing } \\ \text { through a } \\ \text { corporate } \\ \text { portal is } \begin{array}{r}\text { positively } \\ \text { associated } \\ \text { adaptability. }\end{array}\end{array} \\ \text { with } & \end{array}$

Hypothesis 3f: Supporting knowledge sharing through a corporate portal is positively associated with employees' job satisfaction.

4. Knowledge Application.Knowledge application is the process of using knowledge to solve business problems and make business decisions. It includes the retrieval and application of knowledge. As discussed above, corporate reports include rich content that can be accessed and retrieved by users to solve problems and make decisions; corporate portals integrate corporate websites, corporate documents, business content, websites and news.

Knowledge contributes most directly to organizational performance when it is used to make decisions and perform tasks. Knowledge application supports the process through which some individuals utilize knowledge possessed by other individuals without actually acquiring, or learning, that knowledge.

Of course, the process of knowledge application depends on the available knowledge, and knowledge itself depends on the processes of knowledge discovery, capture, and sharing. The better the processes of knowledge discovery, capture, and share, the greater the likelihood that the knowledge needed is available for effective application in decision-making and task performance.
Therefore, knowledge utilization benefits from two processes - routines and direction-that do not involve the actual transfer or exchange of knowledge between the concerned individuals but only the transfer of the recommendations that is applicable in a specific context (Grant (1996)).Directionrefers to the process through which the individual possessing the knowledge directs the action of another individual without transferring to that individual the knowledge underlying the direction.According to Conner and Prahala (1996), direction involves the transfer of instructions or decisions and not the transfer of the knowledge required to make those decisions, and hence it is labeled as knowledge substitution. For example, direction is the process used when a production worker calls an expert to ask him/her how to solve a particular problem with a machine and then proceeds to solve the problem based on the instructions given by the expert. Note the difference between direction and socialization or exchange, where the knowledge is actually transferred to the other person in either tacit form (socialization) or explicit form (exchange).

Routinesinvolve the utilization of knowledge embedded in procedures, rules, and norms that guide future behavior. Routines could be automated through the use of IT, such as in systems that provide help desk agents, field engineers, consultants, and customer end users with specific and automated answers from a knowledge base (Sabherwal and Sabherwal (2007)).

Mechanisms facilitating direction include hierarchical relationships, help desks, and support centers; whereas mechanisms facilitating routines include organizational policies, work practices, and standards.Technologies supporting direction and routines include expert systems, decision support, advisor systems, fault diagnosis (or troubleshooting) systems, and help desk systems (BecerraFernandez et al. (2004: p. 91)). 
Knowledge management can improve the organizational processes; effectiveness, efficiency, and innovativeness through several means, including the provision of workable solutions (through directions and routines), for employees to solve the problems faced in their tasks.

Becerra-Fernandez et al. (2004) predicate that effective knowledge management enables the organization's members to collect relevant knowledge (and information) needed to continually assess the organization's external factors. This enables the organization to be on the top of any change and hence results in fewer surprises for the organization management and consequently reduces the need to modify plans. Knowledge application enables organizations to quickly adapt their processesaccording to the current internal and external environmental conditions, thereby maintaining processeffectiveness in changing times.

Knowledge utilization from corporate portals improve sense making and decision making (De Caralho et al. (2007)), and enhance firms' performance (Teo and Men (2008)). On one hand, Davenport and Prusak (1998), and Liu (2003) argue that the application of relevant knowledge for problem-solving and decision-making improves individuals' learning, and innovation capabilities. On the other hand, knowledge application helps organizations improve their efficiency and reduce costs (Daveport and Prusak (1998)). Furthermore, knowledge application plays a major role on innovation. Drucker (1993) defined innovation as "the application of knowledge to produce new knowledge". Weerawardena et al. (2006) postulate that the higher the learning is, the greater the innovation. In an empirical study in Oman, Al-Busaidi (2005) found that knowledge utilization results in individual benefits.

Moreover, as indicated above, improved employees' learning enhances employees' adaptability. Employees' awareness of new ideas and knowledge prepares them to respond to change and accept it BecerraFernandez et al. (2004). All these perceived benefits result in enhanced employees' job satisfaction.

Thus, the following hypotheses are examined:

Hypothesis 4a: Supporting
knowledge application through a
corporate portal is positively
associated with business processes'
effectiveness.

Hypothesis 4b: Supporting knowledge application through a corporate portal is positively associated with business processes' efficiency.

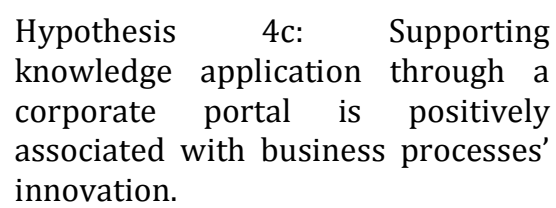

Hypothesis 4d: Supporting knowledge application through a corporate portal is positively associated with employees' learning.

$\begin{array}{lcc}\begin{array}{l}\text { Hypothesis } \\ \text { knowledge } \\ \text { corporate } \\ \text { associated } \\ \text { adaptability. } \\ \text { portal is } \\ \text { with }\end{array} & \begin{array}{l}\text { Supporting } \\ \text { through a } \\ \text { positively } \\ \text { employees' }\end{array} \\ \begin{array}{l}\text { Hypothesis } \\ \text { knowledge }\end{array} & \begin{array}{l}\text { application through a } \\ \text { porporate }\end{array} \\ \text { portal is positively } \\ \text { associated with employees' job } \\ \text { satisfaction. }\end{array}$

\section{Research Methodology}

\section{Investigating Corporate Portal}

The participants of this study represent users of a corporate portal in a private academic institution, ALHOSN University (AHU), in UAE. The AHU academic \& administrative portal is a dynamic web- 
based electronic gateway on the University internal and external data, information and knowledge resources. The portal has several features such as content management, information aggregation, searching and indexing, personalization, single sign interface and content.

The AHU portal enables employees to acquire information and knowledge from different resources and applications.It aggregates and converts them into one single interface. Aggregated information and knowledge are customized and personalized according to the type of users, and their authorization level.

The main home page of AHU site provides links to general services data and general information such as the University's strategy, BOT (Board of Trustees), bylaws, and catalogue; academics; admissions; student services; faculty \& staff services; career vacancies; media relations and other useful links. Through the faculty \& staff services menu button, the main home page also has a login link to allow instructors and administrative staff to login into their personal pages using access authorization.

The content and services of the portal varies according to the users types (i.e., instructors, chair of departments, student advisor, administration staff, head of department). For instance, faculty \& administrative staff's main page (menu choice) includes nine main sections: e-mail section, instructor's portal, Moodle, HR resources, back office, library, staff directory, calendar, and administration portal.The instructor's portal includes a home page, students, attendance, grading, scheduling, links, evaluations, and advisor services.Chair of departments have, in addition, chair services.Users, including instructors and administrators, login into their personal pages using access authorization (username and password).

In the "general section", instructors can: (1) view information about University regulations, workshops, conferences, and other University activities, and (2) link to relevant external websites. In the "academic section", instructors can: (1) find information about their academic work (i.e., class details and schedules, teaching survey results, course offering, missed prerequisites, students, advisees etc.; (2) communicate through email with other external business partners, instructors, students and advisees; and (3) view and share their publication records, working papers, and study abstracts.

In the "services section", instructors can: (1) view several information and content such as employee details, training courses, official trips, borrowed and overdue books etc.; (2) communicate with several University units and request help desk services; (3) link to the University learning management systems (MOODLE), and link to the University Turn-It-In academic honesty program, (4) access different statistical analysis programs, and (5) email system.

In the "academics section", users can (1) view scheduled seminars and workshops, (2) list and view published studies abstracts, (3) list and view working paper series, and (4) look up different colleges', departments', programs' administration, faculty members, and supporting staff.

In the "students section", users can view different contents depending on whether the student is currently enrolled or future student. Current students can use the system to (1) view offered courses, program and university schedule, academic calendar, student's schedule, (2) access MOODLE e-learning system and different statistical analysis programs, (3) view paid and unpaid tuitions, financial assistance (if any), attendance record, and (4) view student handbook. Future students can (1) retrieve all relevant student forms, (2) apply to intended program, (3) file for transcripts, (4) submit special requests, and (5) lookup information about required conditions. 


\section{Data Collection and Sample Profile}

Data were collected through personally handed-in and emailed questionnaire packages from end users of the portal of a medium size private university in $\mathrm{Abu}$ Dhabi (UAE). The authors together with three teaching assistants formed a data collection committee to manage the process.The questionnaire package included the questionnaire together with a detailed paper that explains each of its questions. The University staff phone directory was used as the study population frame.For two weeks, many of the filled-in questionnaires were collected.For another two weeks, the data collection committee made every effort to personally contact each of the University academic and support the staff who did not return or email back their individual filled questionnaires. In some cases, it needed some further explanation of a question or two.Collected questionnaires were checked for completeness.

The total respondents were 84, which represents about $70 \%$ of the invited portal.This 84 sample size represents end users, mainly faculty members. About 54\% of the sample was male, and all the participants had average computer skills.About $72 \%$ of the sample size had academic positions. About $72 \%$ of the participants were faculty members. About $95 \%$ of the sample had at least 2 years work experience, and about $92 \%$ had at least 2 years of portal-use experience, and only $8 \%$ had a year or less of portal experience. About $58 \%$ of the participants were $\mathrm{PhD}$ holders, while $23 \%$ of them were MSc holders and $19 \%$ of them were BSc holders.

\section{Research Questionnaire}

A detailed questionnaire is developed, reviewed, pilot tested, and revised.Reliability and confirmatory factor analyses are employed to check reliability and validity aspects of the dependent and independent side variables.
The questionnaire included the study's constructs along with demographic questions (e.g. gender, age, degree, portal usage experience, work experience, and job title).Construct measurements items were phrased according to a 5-point Likert scale (1=strongly disagree; $2=$ disagree; $3=$ neither agree nor disagree; 4=agree; and $5=$ strongly agree).

To evaluate this study's theoretical model, the questionnaire included 24 items that formed the independent constructs and dependent constructs (see Table 2). KM processes constructs were each assessed by three indicators, while KM benefits constructs were each assessed by two indicators.Constructs related to $\mathrm{KM}$ processes were adopted from BecerraFernandez et al. (2004), while constructs related to KM benefits were self-developed based on Becerra-Fernandez et al. (2004), and relevant literature.

The questionnaire was reviewed by three experts in the field to check the relevancy and clarity of the measurements. The questionnaire was also pre-tested by a small number of portal users to check the clarity of the measurements. Appendix A illustrates the measurements that were included in the questionnaire.

\section{Results}

\section{Construct and Variable Measurement}

Since the constructs in Figures 1 are not directly measurable they must be implied from measured variables. Accordingly, a 'latent variable' design with multiple indicators for each construct was chosen. Constructs are represented by a combination of variables that can be empirically measured. This latent variable design has recently been applied in the management literature (e.g. Bagozzi (1980), Chin (1998), Fornell and Larcker (1981), Peterson (2000); Venkatraman and Ramanujam (1987), Keats and Hitt (1988)). 
The advent of structural equation modeling (SEM) with latent variables has changed the nature of research in strategic management, management information systems, e-business, organizational behavior, marketing, and consumer behavior (Henseler et al. (2009)). As Gefen, Straub and Boudreau (2000: p. 6) point out, 'SEM has become de rigueur in validating instruments and testing linkages between constructs." They further distinguish between two families of SEM techniques: covariance-based techniques, as represented by LISREL, and variance-based techniques, of which partial least squares (PLS) path modeling is the most prominent representative.

\section{Partial Least Squares Analysis Methodology}

A structural modeling approach was chosen to evaluate both error in construct measurement and error in hypothesized relations. Rather than using the well-known LISREL model, partial least squares (PLS) were employed. The choice was motivated by several considerations. First, managerial data do not often satisfy the requirements of multi-normality and interval scaling, or attain the sample size required by maximum-likelihood estimation (ML). Second, the PLS technique avoids many of the restrictive assumptions underlying $\mathrm{ML}$ techniques and ensures against improper solutions and factor indeterminacy.

Data was analyzed using SmartPLS software. PLS is a variance-based structural equation model (SEM) technique that allows path analysis of models with latent variables. A general PLS model is composed of two parts: the structural model and the measurement model.The structural model specifies the relations among the constructs (or latent variables) while the measurement model specifies the relations between the manifest variables and the constructs which they represent. It is assumed for estimation purposes that the unobservables are specified as linear combinations of their respective indicators and, for convenience, that all variables are
standardized.The measurement model enables us to evaluate whether the constructs are measured with satisfactory accuracy.

The evaluation of the model was based first on the assessment of the model measurements by assessing their validity and reliability. Second, it was based on the analysis of the paths of the structural model. The model included 10 constructs (4 exogenous and 6 endogenous) with 24 indicators.The total sample size used for analysis was 84.This sample size is more than sufficient to conduct SEM paths analysis of the research model according to Chin's (1998) recommendations.

\section{Testing Procedure}

A general PLS model is composed of two parts: the structural model and the measurement model. The structural model specifies the relations among the constructs (or latent variables) while the measurement model specifies the relations between the manifest variables and the constructs which they represent. It is assumed for estimation purposes that the unobservable constructs are specified as linear combinations of their respective indicators and, for convenience, that all variables are standardized.The measurement model enables us to evaluate whether the constructs are measured with satisfactory accuracy.

PLS path models are formally defined by two sets of linear equations: The inner model and the outer model. The inner (structural) model specifies the relationships between unobserved or latent variables, whereas the outer (instrument) model specifies the relationships between a latent variable and its observed (or manifest) variables.

In order to simplify the notation of the model and in line with conventional descriptions of PLS, we assume that latent and manifest variables are standardized so that the location parameters can be 
discarded in the following equations. The inner model for relationships between

$$
\xi=\beta \xi+\zeta
$$

Where $\xi$ is the vector of latent variables, $\beta$ denotes the matrix of coefficients of their relationships, and $\zeta$ represents the inner model residuals. The basic PLS design assumes a recursive inner model that is subject to predictor specification. Thus, the inner model constitutes a causal chain

$$
\xi \mid \xi=\beta \xi
$$

PLS path modeling includes two different kinds of outer models: reflective and formative measurement models. A reflective mode has causal relationships from the latent variable to the manifest variables in its block. This is the mode of relationships between each latent variable and its manifest variables in the current study. For example, consider the relationship between "Organizational efficiency" and both"Productivity

$$
\mathrm{X}_{\mathrm{x}}=\Lambda_{\mathrm{x}} \xi+\varepsilon_{\mathrm{x}}
$$

Where $\Lambda$ represents the loading (pattern) coefficients. The outer relationships are also subject to predictor specification implying that there are no correlations

$$
X_{x} \mid \xi=\Lambda_{x} \xi
$$

The formative mode of a measurement model has causal relationships from the manifest variables to the latent variable. This kind of mode of relationship does not exist in the current study model. Therefore, we are not going to show the mathematics of its relationships to limit the length of current presentation.

$$
\left(\sum \lambda_{i}^{2}\right) /\left(\left(\sum \lambda_{i}^{2}\right)+\left(\sum\left(1-\lambda_{i}^{2}\right)\right)\right.
$$

Where $\lambda_{\mathrm{i}}$ is the loading of each measurement item on its corresponding construct. latent variables can be written as:

system (i.e., with uncorrelated residuals and without correlations between the residual term of a certain endogenous latent variable and its explanatory latent variables). Predictor specification reduces Eq. (1) to:

improvement" and "Cost savings" in the study model. This relationship represents such a mode of relationship. Our model hypothesizes that, 'Organizational efficiency" reflects on "Productivity improvements" and "Cost savings." Thus, each manifest variable in a certain measurement model is assumed to be generated as a linear function of its latent variables and the residual $\varepsilon$ :

between the outer residuals and the latent variable of the same block - that reduces Eq. (3) to:

\section{Constructs' Validity and Reliability}

With PLS, the reliability of the measurements was evaluated by internal consistency, and the validity was measured by the average variance extracted (AVE), which refers to the amount of variance in a latent variable captured from its indicators. AVE is calculated as:

While construct validity is an issue of measurement between constructs, reliability is an issue of measurement within a construct. The recommended level 
for internal consistency reliability is at least 0.60 for exploratory research and 0.70 for confirmatory research (Nunnally (1967)), while for AVE, is at least 0.50 (Chin (1998)). Table 1 shows that the study constructs' reliability and AVE are above the recommended levels.

The internal consistency is assessed through the use of the standard Cronbach's $\alpha$.

$$
\text { Coefficient } \alpha \text { is: }(\mathrm{k} / \mathrm{k}-1)\left(1-\left(\sum{\sigma_{\mathrm{i}}}^{2}\right) /\left(\sigma_{\mathrm{t}}{ }^{2}\right)\right.
$$

Where $\mathrm{k}=$ number of parts/items in the scale, $\sigma_{\mathrm{i}}^{2}=$ the variance of item $\mathrm{i}$, and $\sigma_{\mathrm{t}}{ }^{2}=$ the total variance of the scale.

Table 1: Constructs' Validity and Reliability

\begin{tabular}{|l|c|c|c|c|}
\hline \multicolumn{1}{|c|}{ Construct } & Total Items & Reliability & AVE & Cronbach's $\boldsymbol{\alpha}$ \\
\hline K_Discovery & 3 & 0.8879 & 0.7255 & 0.8106 \\
\hline K_Capture & 3 & 0.8161 & 0.5988 & 0.6626 \\
\hline K_Sharing & 3 & 0.8355 & 0.6292 & 0.7080 \\
\hline K_Application & 2 & 0.8385 & 0.6358 & 0.7095 \\
\hline BP_Effectiveness & 2 & 0.8949 & 0.8098 & 0.7658 \\
\hline BP_Efficiency & 2 & 0.8708 & 0.7712 & 0.7039 \\
\hline BP_Innovation & 2 & 0.8314 & 0.7123 & 0.6048 \\
\hline E_Learning & 2 & 0.8814 & 0.7879 & 0.7315 \\
\hline E_Adaptability & 2 & 0.8354 & 0.7173 & 0.6064 \\
\hline E_Satisfaction & 2 & 0.9050 & 0.8264 & 0.7911 \\
\hline
\end{tabular}

The factor loadings from the confirmatory factor analysis (CFA) provide evidence for convergent validity as all items load sufficiently high on the corresponding constructs. They all exceed the threshold value of 0.50 suggested by Peterson (2000). With loadings between 0.71 and 0.89 , Table 2 results indicate satisfactory convergent validity for all constructs in the theoretical model. 
Table 2: Measurements Statistics

\begin{tabular}{|c|c|}
\hline Measurements & Loading \\
\hline \multicolumn{2}{|l|}{ Knowledge Discovery } \\
\hline DISC1 & 0.8151 \\
\hline DISC2 & 0.8973 \\
\hline DISC3 & 0.8408 \\
\hline \multicolumn{2}{|l|}{ Knowledge Capture } \\
\hline CAPT1 & 0.8745 \\
\hline CAPT2 & 0.7184 \\
\hline CAPT3 & 0.7179 \\
\hline \multicolumn{2}{|l|}{ Knowledge Sharing } \\
\hline SHAR1 & 0.8041 \\
\hline SHAR2 & 0.7420 \\
\hline SHAR3 & 0.8310 \\
\hline \multicolumn{2}{|l|}{ Knowledge Application } \\
\hline APPL1 & 0.7262 \\
\hline APPL2 & 0.7622 \\
\hline APPL3 & 0.8938 \\
\hline \multicolumn{2}{|l|}{ Business Process Effectiveness } \\
\hline EFFE1 & 0.8880 \\
\hline EFFE2 & 0.9116 \\
\hline \multicolumn{2}{|l|}{ Business Process Efficiency } \\
\hline EFFI1 & 0.8907 \\
\hline EFFI2 & 0.8655 \\
\hline \multicolumn{2}{|l|}{ Business Process Innovation } \\
\hline INN01 & 0.7885 \\
\hline INNO2 & 0.8961 \\
\hline \multicolumn{2}{|l|}{ Employee Learning } \\
\hline LEAR1 & 0.8755 \\
\hline LEAR2 & 0.8997 \\
\hline \multicolumn{2}{|l|}{ Employee Adaptability } \\
\hline ADAP1 & 0.8599 \\
\hline ADAP2 & 0.8338 \\
\hline \multicolumn{2}{|l|}{ Employee Job Satisfaction } \\
\hline SATI1 & 0.8951 \\
\hline SATI2 & 0.9229 \\
\hline
\end{tabular}

To achieve the discriminant validity of the constructs, Fornell and Larcker (1981) suggest that the square root of the average variance extracted (AVE) of each construct should exceed the correlations shared between the constructs and the other constructs in the model. Table 3 shows that the model constructs satisfy that rule, as the square root of the AVE (on the diagonal) for each construct, is greater than the correlations with the other constructs. Thus, all the model's constructs have a satisfactory reliability and validity measurements. 
Table 3: Construct Correlation and Discriminant Validity

\begin{tabular}{|l|l|l|l|l|l|l|l|l|l|l|}
\hline & DISC & CAPT & SHAR & APPL & EFFE & EFFI & INNO & LEAR & ADAP & SATI \\
\hline DISC & 0.8518 & & & & & & & & & \\
\hline CAPT & 0.6527 & 0.7738 & & & & & & & & \\
\hline SHAR & 0.6933 & 0.6933 & 0.7932 & & & & & & & \\
\hline APPL & 0.6712 & 0.6142 & 0.7025 & 0.7974 & & & & & & \\
\hline EFFE & 0.5993 & 0.5718 & 0.5264 & 0.5468 & 0.8999 & & & & & \\
\hline EFFI & 0.4784 & 0.5598 & 0.5026 & 0.5082 & 0.4548 & 0.8782 & & & & \\
\hline INNO & 0.4221 & 0.4784 & 0.5525 & 0.4541 & 0.5727 & 0.3746 & 0.8440 & & & \\
\hline LEAR & 0.5367 & 0.5151 & 0.5166 & 0.4661 & 0.4352 & 0.5827 & 0.4422 & 0.8876 & & \\
\hline ADAP & 0.4077 & 0.4077 & 0.4393 & 0.4228 & 0.3502 & 0.5066 & 0.4269 & 0.6075 & 0.8469 & \\
\hline SATI & 0.6415 & 0.5245 & 0.5646 & 0.6128 & 0.6068 & 0.6518 & 0.4837 & 0.7130 & 0.6638 & 0.9091 \\
\hline
\end{tabular}

\section{Model Evaluation and Paths Analysis}

With PLS, $\mathrm{R}^{2}$ values are used to evaluate the predictive relevance of a structural model for the dependent latent variables, and the paths coefficients are used to assess the effects of the independent variables.The significance of the model paths were tested by T-tests. Bootstrapping technique was utilized to test the significance of the PLS estimates of path coefficients.

Table 4: Model Evaluation and Paths Analysis

\begin{tabular}{|l|l|l|l|l|l|l|}
\hline $\begin{array}{l}\text { Constructs } \\
\left(\mathbf{R}^{2} \mathbf{)}\right.\end{array}$ & $\begin{array}{l}\text { Effectiveness } \\
\mathbf{( 0 . 4 3 3 )}\end{array}$ & $\begin{array}{l}\text { Efficiency } \\
\mathbf{( 0 . 3 6 4 )}\end{array}$ & $\begin{array}{l}\text { Innovation } \\
\mathbf{( 0 . 3 2 7})\end{array}$ & $\begin{array}{l}\text { Learning } \\
\mathbf{( 0 . 3 5 4 )}\end{array}$ & $\begin{array}{l}\text { Adaptability } \\
\mathbf{( 0 . 2 5 8 )}\end{array}$ & $\begin{array}{l}\text { Satisfaction } \\
\mathbf{( 0 . 4 8 0 )}\end{array}$ \\
\hline Discovery & $0.3010^{* * *}$ & 0.0747 & 0.0183 & $0.2635^{* *}$ & $0.2524^{* *}$ & $0.3594^{* * *}$ \\
\hline Capture & $0.2443^{* *}$ & $0.3316^{* * *}$ & $0.1563^{*}$ & $0.1909^{*}$ & 0.0781 & 0.0555 \\
\hline Sharing & 0.0438 & 0.0885 & $0.3735^{* * *}$ & $0.1778^{*}$ & $0.1476^{*}$ & 0.1037 \\
\hline Application & $0.1639^{*}$ & $0.1922^{*}$ & 0.0835 & 0.0471 & 0.1017 & $0.2646^{* *}$ \\
\hline
\end{tabular}

Table 4 shows the $R^{2}$ values of the endogenous constructs. The model explains $48.0 \%$ of the variance in employees' job satisfaction, $43.3 \%$ of the variance in business processes' effectiveness, $36.4 \%$ of the variance in business processes' efficiency, $35.4 \%$ of the variance in employees' learning, $32.7 \%$ of the variance in business processes' innovation, and
$25.8 \%$ of the variance in employees' adaptability.

Table 4 also shows that the paths' coefficients analysis between the exogenous constructs (KM processes) and the endogenous constructs (benefits).The statistical significance of paths' coefficients was measured by t-values. 


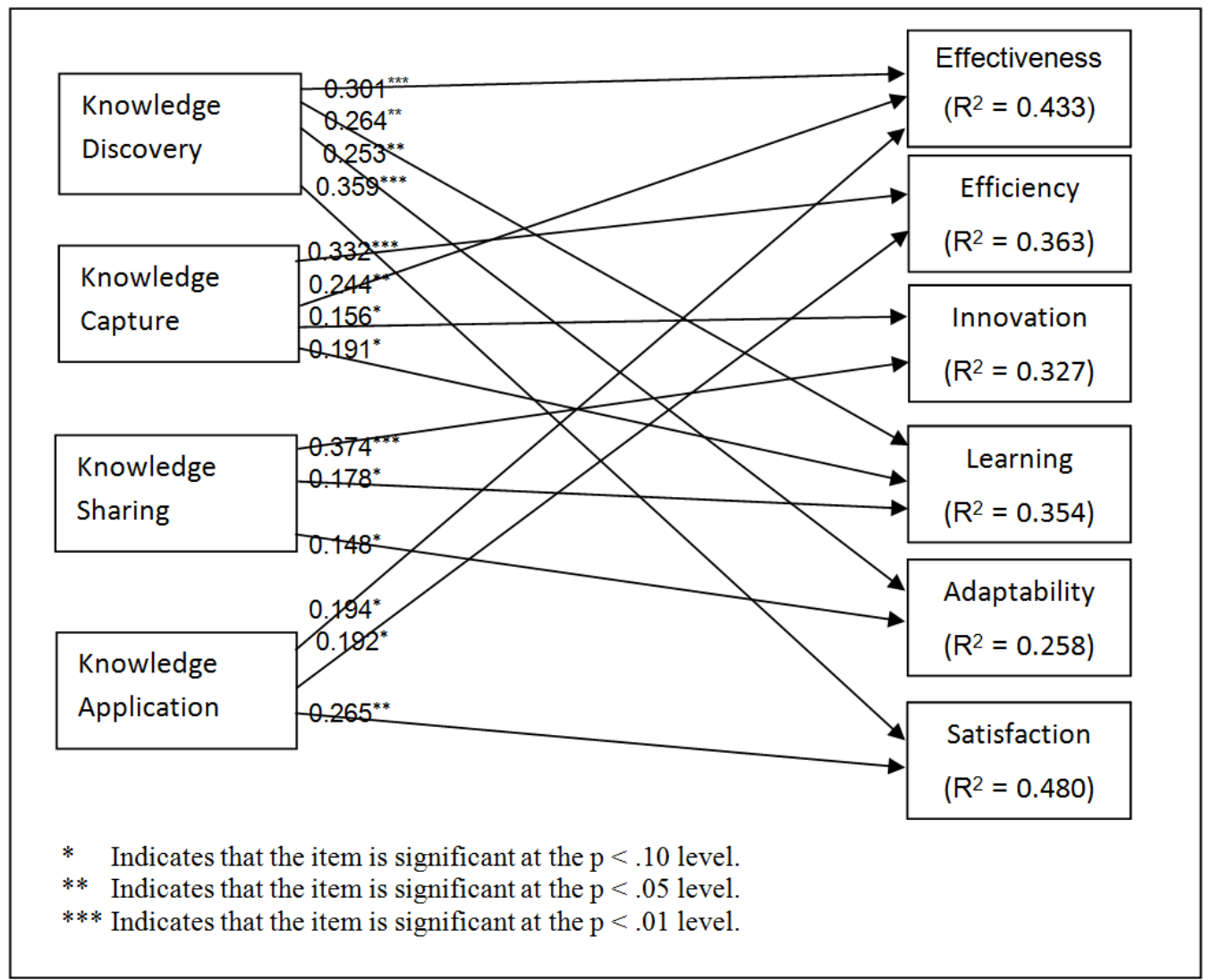

Figure 2: Significant Paths' Coefficients between the Model Constructs

The analysis shows that, first, providing tools that support knowledge discovery through a corporate portal was significantly positively associated with business processes' effectiveness (Beta of 0.301 and p-value $<0.01$ ), was significantly positively associated with employees' job satisfaction (Beta of 0.359 and p-value $<0.01$ ), was significantly positively associated with employees' learning (Beta of 0.2635 and pvalue <0.05), and was significantly positively associated with employees' adaptability (Beta of 0.252 and p-value < 0.05): thus Hypotheses $1 \mathrm{a}, 1 \mathrm{~d}, 1 \mathrm{e}$, and $1 \mathrm{f}$ are supported for knowledge discovery.Second, providing tools that support knowledge capture through a corporate portal was significantly positively associated with business processes' efficiency (Beta of 0.332 and $p$-value $<0.01$ ), was significantly positively associated with business processes' effectiveness (Beta of 0.244 and p-value $<0.05$ ), was significantly positively associated with employees' learning (Beta of 0.191 and p-value < 0.1), and was significantly positively associated with business processes' innovation (Beta of 0.156 and $p$-value < 0.1 ): hence Hypotheses $2 \mathrm{a}, 2 \mathrm{~b}, 2 \mathrm{c}$, and $2 \mathrm{~d}$ are supported for knowledge capture. Third, providing tools that support knowledge sharing through a corporate portal was significantly positively associated with business processes' innovation (Beta of 0.374 and p-value < 0.01), was significantly positively associated with employees' learning (Beta of 0.178 and p-value < 0.1 ), and was significantly positively associated with employees' adaptability (Beta of 0.148 and p-value < 0.1): therefore Hypotheses 3c, 3d, and $3 \mathrm{e}$ are supported for knowledge sharing. Fourth, providing tools that 
support knowledge application through a corporate portal was significantly positively associated with employees' job satisfaction (Beta of 0.265 and p-value $<0.05$ ), was significantly positively associated with business processes' effectiveness (Beta of 0.164 and p-value < 0.1), and was significantly positively associated with business processes' efficiency (Beta of 0.192 and p-value < 0.1); thus Hypotheses $4 \mathrm{a}, 4 \mathrm{~b}$, and $4 \mathrm{f}$ are supported for knowledge application.

Figure 2 depicts the above detailed significant paths in the study. Only significant coefficients are shown.

\section{Discussion of Findings}

A corporate portal provides a gateway into corporate internal and external information and knowledge resources. Corporate portals are playing a major role on organizational knowledge management by incorporating tools for efficient access of organizational information knowledge, communication and collaboration.

The objective of this study was to identify the impact of supporting knowledge management processes (discovery, capture, sharing, and application) through a corporate portal on business processes' effectiveness, efficiency, and innovation; and employees' learning, adaptability, and job satisfaction.

The results suggested that supporting knowledge management through corporate portal had significant impacts on organizational business processes and employees. First, consistent with the literature and previous research knowledge sharing had the highest impact on business processes and employees. Knowledge sharing had a significantly positive impact on business processes' innovation (Beta = $0.374)$, employees' learning (Beta $=0.178$ ), and employees' adaptability (Beta = 0.148).These findings are consistent with Stewart (2000), Becerra-Fernandez et al.
(2004), Chang and Lee (2007), Jiang and Lia (2008), and Al-Busaidi (2010).

Second, knowledge discovery had also significant impact on business processes and employees. However, it was a little less than the impact of knowledge sharing. Knowledge discovery had a significantly positive impact on business effectiveness (Beta $=0.301)$, but not efficiency, employees' learning (Beta $=0.264$ ), employees' adaptability (Beta $=252$ ), and employees' satisfaction (Beta $=0.359$ ). These findings are consistent withBecerraFernandez et al. (2004), Davenport and Prusak (1998), Chang and Lee (2007), Jiang and Lia (2008), DeLone and McLean (2003), Jennex (2008), and Jennex and Olfman (2006).

In fact this result makes a lot of practical sense. If the first phase of KM life cycle gets hold of the right knowledge needed by the organization, then the whole system will be able to furnish this knowledge through the following phases in the KM life cycle and vice versa. If this argument is valid, one would expect that knowledge capture would have the next highest impacts in significance.

Third, although knowledge capture had also significant impact on business processes and employees, this impact was less than the impact of each of knowledge sharing and knowledge discover, as expected. Knowledge capture had a significantly positive impact on business processes' efficiency (Beta $=0.332$ ), business processes' effectiveness (Beta $=0.244)$, business processes' innovation (Beta = 0.156), and employees' learning (Beta = 0.191). These findings are consistent with Norman (2002), Becerra-Fernandez et al. (2004), Davenport and Prusak (1998), Chang and Lee (2007), and Jiang and Lia (2008). However these findings disagree with Al-Busaidi (2010).

It is interesting that although knowledge discovery has more impact on employees than on business processes, knowledge 
capture has more impact on business processes than on employees.

Finally, knowledge application had the lowest impact on business processes and employees, compared to the other $\mathrm{KM}$ processes. The analysis showed that providing tools that support knowledge application through a corporate portal had a significantly positive impact on employee satisfaction (Beta $=0.265)$, business processes' effectiveness (Beta $=0.164)$, and business processes' efficiency (Beta = 0.192). These results are consistent with AlBusaidi (2005), Davenport and Prusak's (1998), and Liu (2003).

Investigating which of the business processes or employees' benefits are influenced more by the KM processes, one finds that both business processes' effectiveness and employees' job satisfaction are affected the highest. The correlations analysis in Table 3 provided some insights on this $\mathrm{KM}$ investigation. First, the high correlations between the employees' job satisfaction and the other business processes' and employees' benefits, suggest that the employees' job satisfaction may be associated with the net benefits gained from the system use.Thus, supporting KM processes through a corporate portal does not directly impact employees' job satisfaction (except for knowledge discovery and application), but indirectly through the other perceived net benefits (business processes' and employees' benefits). This is similar to DeLone and McLean's (2003), Jennex's (2008), Jennex and Olfman's (2006), and AlBusaidi's (010) proposition of user satisfaction and net benefits.Second, the high correlation between employees' learning and adaptability $(r=0.61)$ indicated the strength of the relationship between the two. Employees' adaptability is highly related to their learning capability Becerra-Fernandez et al. (2004).Third, the high correlation between knowledge sharing and knowledge application ( $\mathrm{r}=$ 0.71) illustrates the importance of knowledge sharing for effective knowledge
application.Finally, the high correlation between each pair of the knowledge management processes illustrates a strong relationship between these processes for effective knowledge management BecerraFernandez et al. (2004).

\section{Study Conclusion and Limitations}

\section{Study Implications}

In conclusion, this study provided some implications for practitioners and researchers. First, this study tackled an under investigated area in portals and KM literature, the impact of supporting KM through corporate portal on employees and business processes. The study confirmed for practitioners and researchers that the deployment of organizational KMS, specifically corporate portals, results in numerous benefits for business processes and employees.The study also provided measurements for evaluating such benefits. Second, the study empirically showed that a corporate portal is a promising technology for organizational knowledge management as it can be used as a tool to discover, capture, share, and apply organizational knowledge.A corporate portal provides employees with a rich shared information work space to discover, capture, share, and apply knowledge.Third, the study showed that the major impact of KMS results from the sharing knowledge. The benefits of KMS are achieved by the sharing of knowledge to carry out business processes, solve business problems, and make business decisions. Providing mechanisms and tools to support knowledge discovery and capture are important but not enough to fully harness the benefits of a KMS. Supporting and ensuring knowledge sharing will do that.Fourth, this study showed that corporate portal is a promising technology for organizational knowledge management at a Middle Eastern organization where countries need to increase their knowledge base, invest in educating their people, and take advantage of new technologies for acquiring and disseminating knowledge.Fifth, the study 
illustrated the utilization of corporate portal for organizational knowledge management at an academic institution.Thus, this study provided measurements for academic institutions to evaluate the capability of their portals to support their organizational knowledge management.

\section{Study Limitations}

It is worthy to mention that the current study, like all others, is subject to some limitations. Generalizability of the analysis results may be perceived by certain reviewers as limited by variables included in the study model, study sample, items included in survey analysis, and nature of research.

\section{Suggestions for Future Research}

The UAE is a member of the GCC countries which represent one distinct culture block. If this is true, then it would be interesting to test the same study model on data from Saudi Arabia, Kuwait, or Qatar (all are members of the same cultural block).Comparison between results from these different countries that relate to the same national block would constitute a real test of the study model and the effect of these culture-related variables.

The current study used data that are collected from a medium-size UAE university to investigate the effect of KM processes' support through a corporate portal on business processes' and employees' benefits. All staff members that were familiar with the university portal and were interested in participating in the study, were included in the study frame.This had the advantage of providing for a large population to select the sample from to satisfy different statistical analysis considerations. Also, it provides for enriching the analysis with reasonable degree of diversity of work, background, experience with computers \& corporate portals. However, this was on the expense of work homogeneity of these staff members. It may be feasible in the future to have a larger number of faculty members at a large university to collect data from. This would control of work heterogeneity and test the effect of work homogeneity.

On one hand, it is possible that the factors being examined might involve also the impact of data security and the protection of intellectual property and know-how of the knowledge discovery, capture, sharing, and application processes. It would be interesting to design a further new study to investigate how to adjust the study factors for these impacts.

On the other hand, there is a potential plan for the research repetition after a 5 to 10 years period of time. It would be interesting to include the same research sample to see the changes and potential improvements in the researched areas.

The current study's focus was on the experience of a UAE university academic and administrative staff's perceptions of knowledge management.Culture related variables are significant determinants of knowledge management use and success.

The current study is based on BecerraFernandez et al.'s (2004) model to investigate the functional relationships between knowledge management processes, on one hand, and business processes; and employees' benefits, on the other hand. It is always interesting to investigate these kinds of relationships under another theoretical framework.This would represent a feasible research project for the future.

Most of the participants in the current study were informed, as promised earlier, about the results.More than $80 \%$ of them agree with the study findings.Based on the University directions, a detailed report about the study findings is underway. The report mainly highlights the implementation of specific improvements in existing portal based on identified gaps and drawbacks. 


\section{Acknowledgement}

We are grateful to the anonymous reviewers whose constructive comments have improved the quality of the paper substantially.

\section{References}

1.Akporiaye, B. (2007). "A Portal-Based Approach to Business Performance Management," Beyenetwork.[Online], [Retrieved September 20, 2013], http://www.b-eye-

network.com/view/3883.

2.Alavi, M. \&Leidner, D. E. (1999). "Knowledge Management Systems: Issues, Challenges, and Benefits," Communications of the AIS 1 (7), 2-37.

3.Alavi, M. \&Leidner, D. E. (2001). "Review: Knowledge Management and Knowledge Management Systems," Conceptual Foundations and Research Issues 25 (1), 107136.

4.Alavi, M., Kayworth, T. R.\&Leidner, D. E. (2006). "An Empirical Examination of the Influence of Organizational Culture on Knowledge Management Practices," Journal of Management Information Systems 22 (3), 191-224.

5.Al-Busaidi, K. A. (2005). "A SocioTechnical Investigation of the Determinants of Knowledge Management Systems Usage," Unpublished Doctoral Dissertation, Claremont Graduate University, Claremont, CA.

6.Al-Busaidi, K. A. (2009). "Strengths and Weaknesses of Corporate Portal," Proceedings of the 13th International Business Information Management Association (IBIMA), ISBN: 978-0-98214892-1, 9-10 November 2009, Marrakech, Morocco, 875-882.

7.Al-Busaidi, K. A. (2010). "The Impact of Supporting Organizational Knowledge Management through a Corporate Portal on
Employees and Business Processes," International Journal of Knowledge Management 6 (3), 44-64.

8.Al-Busaidi, K. A. \&Olfman, L. (2005). “An Investigation of the Determinants of Knowledge Management Systems Success in Omani Organizations," Journal of Global Information Technology Management 3 (3), 6-27.

9.Argote, L. \& Ingram, P. (2000). "Knowledge Transfer: A Basis for Competitive Advantage in Firms," Organizational Behavior and Human Decision Processes 82 (1), 150-169.

10.Awad, E. M. \&Ghaziri, H. M. (2004).'Knowledge Management,' PrenticeHall, Upper Saddle, New Jersey.

11.Bagozzi, R. (1980). Causal Models in Marketing, Wiley, New York.

12.Barney, J. B. (1995). "Looking Inside for Competitive Advantage," The Academy of Management Executive 9 (4), 49-61.

13.Becerra-Fernandez, I., Gonzalez, A. \&Sabherwal, R. (2004).'Knowledge Management Challenges, Solutions, and Technologies,' Pearson Education, New Jersey.

14.Becerra-Fernandiz, I. \&Sabherwal, R. (2010).Knowledge Management: Systems and Processes, M.E. Sharpe, New York.

15.Benbaya, H., Passiante, G. \&Belbaly, N. A. (2004). "Corporate Portal: A Tool for Knowledge Management Synchronization," International Journal of Information Management 24, 201-220.

16.Bennet, D. \&Bennet, A. (2003). 'The Rise of the Knowledge Organization,' Handbook of Knowledge Management: Knowledge Matters, Hosapple, C. W. (ed), SpringerVerlag, Heidelberg.

17.Bhatt, G. D. (2000). “Organizing Knowledge in the Knowledge Development 
Cycle," Journal of Knowledge Management 4 (1), 15-26.

18.Bontis, N. (2003). 'HR's Role in Knowledge Management,' Canadian HR $\begin{array}{llll}\text { Reporter } & 16 & \text { (5), }\end{array}$

19.Bray, D. A. (2006). "Literature Review Knowledge Management Research at the Organizational Level," ResearchGate [Online], [Retrieved October 01, 2013], http://ssrn.com/abstract=991169.

20.Brown, J. S. \&Duguid, P. (1991). "Organizational Learning and Communitiesof-Practice: Toward a Unified View of Working, Learning, and Innovation," Organization Science 2 (1), 40-57.

21.Chang, S. \& Lee, M. (2007). 'The Effects of Organizational Culture and Knowledge Management Mechanisms on Organizational Innovation: An Empirical Study in Taiwan,' The Business Review-Cambridge 7 (1), 295301.

22.Chin, W. W. (1998). "The Partial Least Square Approach to Structural Equation Modelling," Modern Methods for Business Research, Marcoulides, G. A. (Ed), Lawrence Erlbaum Associates, London, 295-336.

23.Chong, S. C. (2006). "KM Critical Success Factors: A Comparison of Perceived Importance versus Implementation in Malaysian ICT Companies," The Learning Organization 13 (3), 230-256.

24.Cohen, W. M. \&Levinthal, D. A. (1990). "Absorptive Capacity: A New Perspective on Learning and Innovation," Administrative Science Quarterly 35 (1), 128-52.

25.Courtney, J. F., DeSanctis, G. \& Kasper, G. M. (1983). "Continuity in MIS/DSS Laboratory Research: The Case for a Common Gaming Simulator," Decision $\begin{array}{llll}\text { Sciences } & 14 & \text { (3), } & \text { 419-439. }\end{array}$

26.Daniels, P. W. \& Bryson, J. R. (2002). "Manufacturing Services and Serving Manufacturing: Knowledge-Based Cities and
Changing Forms of Production," Urban Studies 39 (5/6), 977-991.

27.Davenport. I. \&Prusak, I. (1998). 'Working Knowledge,' Harvard Business School Press, Boston.

28.De Carvalho, R. B., Ferreira, M. A. T., Choo, C. W. \& Da Silva, R. V. (2007). The Effects of Enterprise Portals on Knowledge Management Projects, Encyclopedia of Portal Technologies and Applications, Tatnall, A. (Ed), IGI Global, Hershey, PA, 296-303.

29.DeLone, W. H. \& McLean, E. R. (2003). "The DeLone and McLean Model of Information Systems Success: A Ten- Year Update," Journal of Management Information Systems 19 (4), 9-30.

30.Denning, S. (2000).The Springboard: How Storytelling Ignites Action in Knowledge-Era Organizations. ButterworthHeinemann,

Boston.

31.Dermol, V. (2011). "Incentives for Knowledge Management and Organizational Performance," Management, Knowledge, and Learning International Conference, 345-353.

32.Dickson, G. W., Senn, J. A. \&Charvany, N. L. (1977). "Research in Management Information Systems: The Minnesota Experiments," Management Science 23, 913923.

33.Fornell, C. \&Larcker,D. F. (1981). "Evaluating Structural Equation Models with Unobservable Variables and Measurement Error," Journal of Marketing Research 18, 3950.

34.Ganguly, A. R., Gupta, A. \& Khan, S. (2005). Data Mining and Decision Support for Business and Science, Encyclopedia of Data Warehousing and Mining, Wang, J. (Ed), Idea Group.

35.Gefen, D., Straub, D. W. \& Boudreau, M. C. (2000). "Structural Equation Modeling and Regression: Guidelines for Research 
Practice," Communications of the Association for Information Systems 4 (7), 1-78.

36.Gold, A. H., Malhorta, A. \&Segars, A. H. (2001). "Knowledge Management: An Organizational Capabilities Perspective," Journal of Management Information Systems 18 (1), 185-214.

37.Grant, R. M. (1996). "Toward a Knowledge-Based Theory of the Firm," Strategic Management Journal 17, 109-122.

38.Gurgué, A. (2002). 'Living and Breathing Portals,' Corporate Portals Empowered with $X M L$ and Web Services, 273-284.

39.Heisig, P. (2009). "Harmonisation of Knowledge Management - Comparing 160 KM Frameworks around the Globe," Journal of Knowledge Management 13 (4), 4-31.

40.Henseler, J., Ringle, C. M. \&Sinkovics, R. R. (2009). "The Use of Partial Least squares Path Modeling in International Marketing," Advances in International Marketing 20, 277-319.

41.Herschel, R. T. \& Jones, N. E. (2005). "Knowledge Management and Business Intelligence: The Importance of Integration," Journal of Knowledge Management 9 (4), 45-55.

42.Holsapple, C. W. (ed) (2003). Handbook of Knowledge Management: Knowledge Matters, Vol. 1, Springer-Verlag, Heidelberg.

43.Ives, B., Hamilton, S. \& Davis, G. B. (1980). "A Framework for Research in Computer-Based Management Information Systems," Management Science 26, 982-993.

44.Jarvenpaa, S. L., Dickson, G. W. \&DeSanctis, G. (1985). "Methodological Issues in Experimental IS Research: Experiences and Recommendations," MIS Quarterly $9, \quad 141-156$.

45.Jenkins, A. M. (1977). 'An Investigation of Some Management Information System Design Variables and Decision Making
Performance: A Simulation Experiment,' Unpublished doctoral thesis.University of Minnesota.

46.Jennex, M. E. (2008). "Impacts from Using Knowledge: A Longitudinal Study from a Nuclear Power Plant," International Journal of Knowledge Management 4 (1), 5164.

47.Jennex, M. E. \&Olfman, L. (2006). "A Model of Knowledge Management Success," International Journal of Knowledge Management 2 (3), 51-68.

49.Jensen, M. C. \&Meckling, W. H. (1996).'Specific and General Knowledge, and Organizational Structure, Knowledge Management \& Organizational Design', Myers, P. S. (Ed), Butterworth-Heinemann, Newton, MA.

50.Jiang, X. \&Lia, Y. (2008). "An Empirical Investigation of Knowledge Management and Innovative Performance: The Case of Alliances," Research Policy38 (2), 358-368.

51.Keats, B. W. \&Hitt, M. A. (1988).“A Causal Model of Linkages among Environmental Dimensions, Macro Organizational Characteristics, and Performance," Academy of Management Journal 31, 570598.

52.Lee, H. \& Choi, B. (2003). 'Knowledge Management Enablers, Process, and Organizational Performance: An Integrative View and Empirical Examination,' Journal of Management Information Systems 20 (1), 179-228.

53.Li, P. \& Wood, W. (2005). 'Portals in the Academic World: Are They Meeting Expectations?,' Journal of Computer Information Systems 45 (4), 50-55.

54.Liu, P. L. \& Tsai, C. H. (2007)."Effect of Knowledge Management Systems on Operating Performance: An Empirical Study of hi-tech Companies Using the Balanced Scorecard Approach," International Journal of Management 24 (4), 734-741. 
55.Liu, S. C. (2003). 'A Study of factors that Facilitate Use of Knowledge Management Systems and the Impact of Use on Individual Learning,' Unpublished Doctoral Dissertation, Claremont Graduate University, Claremont, CA.

56.Lo, K. C. \& Chin, K. S. (2009). "UserSatisfaction-Based Knowledge Management Performance Measurement," The International Journal of Quality \& Reliability Management, 449-468.

57.Lyles, M. A. \& Salk, J. E. (1996). "Knowledge Acquisition from Foreign Parents in International Joint Ventures: An Empirical Examination in the Hungarian Context," Journal of International Business Studies 27 (5), 877-903.

58.Malone, D. (2002). "Knowledge Management: A Model for Organizational Learning," International Journal of Accounting, Information Systems 3, 111-123.

59.Mohammed, W. \& Jalal, A. (2011). "The Influence of Knowledge Management System (KMS) on Enhancing Decision Making Process (DMP)," International Journal of Business and Management 6 (8), 216-229.

60.Nevo, D. \& Chan, Y. E. (2007). "A Delphi Study of Knowledge Management Systems: Scope and Requirements," Information \& Management 44, 583-597.

61.Newell, S., Huang, J. C., Galliers, R. D. \& Pan, S. L. (2003). "Implementing Enterprise Resource Planning and Knowledge Management Systems in Tanden: Fostering Efficiency and Innovation Complementarily," Information and Organization 13, 25-52.

62.Nonaka, I. \& Takeuchi, H. (1995). 'The Knowledge Creating Company: How Japanese Companies Create the Dynamics of Innovation,' Oxford University Press, New York.

63.Nonaka, I. (1994). "A Dynamic Theory of
Organizational Knowledge Creation," Organization Science 5 (1), 14-37.

64.Norman, P. M. (2002). "Protecting Knowledge in Strategic Alliances: Resource and Relational Characteristics," The Journal of High Technology Management Research 13, 177-202.

65.Nunnally, J. C. (1967). Psychometric Theory, McGraw-Hill, New York.

66.Park, Y. \& Kim, S. (2006). "Knowledge Management Systems for Fourth Generation R \& D: KNOWVATION," Technovation 26 (56), 595-602.

67.Peterson, R. A. (2000). "A Meta-Analysis of Variance Accounted for and Factor Loadings in Exploratory Factor Analysis," Marketing Letters 11, 261-275.

68.Pino, M. \&Doucet, A. V. (2007). "An Educational Resource for Information Literacy in Higher Education: Functional and Users Analyses of the e-COMS Academic Portal," Scientometrics 72 (2), 225-252.

69.Robles-Flores, J. A. (2011).'Knowledge Management Systems and their Impact on Knowledge-Intensive Business Processes,' Unpublished PhD Dissertation, Arizona State University, Tempe.

70.Sabherwal, R. (2008). "KM and BI: From Mutual Isolation to Complementarity and Synergy," Cutter Consortium Executive Report 8 (8), 1-18.

71.Sedighi, A. (2006). 'An Indispensible Guide to Knowledge Management Systems,' IEEE Software 23 (1), 118.

72.Seleim, A. \& Khalil, O. (2007). "Knowledge Management and Organizational Performance in the Egyptian Software Firms," International Journal of Knowledge Management 3 (4), 37-66.

73.Shapira, P., Youtie, J., Yogeesvaran, K. \&Jaafar, Z. (2006). "Knowledge Economy Measurement: Methods, Results and 
Insights from the Malaysian Knowledge Content Study," Research Policy 35 (10), 1522-37.

74.Sharda, R., Barr, S. H. \& McDonnell, J. C. (1998). "Decision Support System Effectiveness: A Review and an Empirical Test," Management Science 34 (2), 139-159.

75.Skyrme, D. J. (2001).Capitalizing on knowledge: From E-Business to K-Business, Butterworth Heinemann, Oxford.

76.Song, J. H. (2008). 'The Key to Organizational Performance Improvement: A Perspective of Organizational Knowledge Creation," Performance Improvement Quarterly 21 (2), 87-102.

77.Stewart, T. A. (2000). "The House that Knowledge Built," Fortune, October 2, 2000.

78.Storck, J. \& Hill, P. A. (2000). “Knowledge Diffusion through Strategic Communities," Sloan Management Review 41 (2), 63-74.

79.Teece, D. J. (1998). “Capturing Value from Knowledge Assets: the New Economy, Markets for Know-How and Intangible Assets," California Management Review 40 (3), 55-79.

80.Teo, T. S. H. \& Men, B. (2008). "Knowledge Portals in Chinese Consulting Firms: A Task-Technology Fit Perspective," European Journal of Information 17, 557574 ,

81.Tiwana, A. (2004). "An Empirical Study of the Effect of Knowledge Integration on Software Development Performance,"
Information and Software Technology 46 (13), 899-906.

82.Turban, E., Sharda, R. E. \&Delen, D. (2011).'Decision Support and Business Intelligence Systems,' Pearson, Boston.

83.Uriarte, F. (2008).'Introduction to Knowledge Management,' ASEAN Foundation, Jarkatar, Indonesia.

84.Venkatraman, N. \&Ramanujam, V. (1987)."Planning system Success: A Conceptalization and an Operational Model," Management Science 33 (6), 687 705.

85.Weerawardena, J., O'Cass, A. \& Julian, C. (2006). "Does Industry Matter? Examining the Role of Industry Structure and Organizational Learning in Innovation and Brand Performance," Journal of Business Research 59 (1), 37-45.

86.Wu, J. H. \& Wang, Y. M. (2006)."Measuring KMS Success: A Respecification of the DeLone and McLean's Model," Information \& Management 43, 728739.

87.Yang, Z., Cai, S., Zhoue, Z. \& Zhou, N. (2005). "Development and Validation of An Instrument to Measure User Perceived Service Quality of Information Presenting Web Portals," Information \& Management 42, 575-589.

88.Zhang, D. S. \& Zhao, J. I. (2006).'Knowledge Management in Organizations,' Journal of Database Management 17 (1), i-viii. 